\title{
Erratum to: Simultaneous determination of trimethylamine, formaldehyde and benzene via the cataluminescence of $\mathrm{In}_{3} \mathrm{LaTi}_{2} \mathrm{O}_{10}$ nanoparticles
}

\author{
Kaowen Zhou ${ }^{1,2} \cdot$ Jichao Xu ${ }^{1,3} \cdot$ Chunxiu Gu ${ }^{1,2} \cdot$ Chunjuan Hou ${ }^{1,2} \cdot$ Huirong Ren ${ }^{1}$
}

Published online: 16 June 2017

(C) Springer-Verlag GmbH Austria 2017

\section{Erratum to: Microchimica Acta}

DOI 10.1007/s00604-017-2221-4

The original version of this article, unfortunately, contained error in the acknowledgement section. Given in this article is the correct acknowledgement statement.

Acknowledgements This work was supported by Beijing Municipal Natural Science Foundation (CN) (Grant No.2152013), Key Projects of Science and Technology Plan from Beijing Municipal Education Commission (CN) (KZ201311417038), State 863 Projects (2014AA022002) and Scientific Research Project from Facing Characteristic Discipline of Beijing Union University (KYDE40201703).

The online version of the original article can be found at http://dx.doi.org/ 10.1007/s00604-017-2221-4

Kaowen Zhou

zhoukaowen@buu.edu.cn

1 Biochemical Engineering College, Beijing Union University,

Beijing 100023, China

2 Beijing Key Laboratory of Biomass Waste Resource Utilization, Beijing 100023, China

3 Qingdao Institute for Food and Drug Control, Qingdao 266071, China 